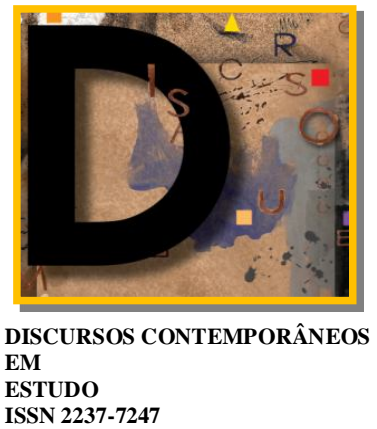

\title{
LEGISLAÇÃO E INCLUSÃO EDUCACIONAL À LUZ DA ADC
}

Candice Assunção (UnB)

Este trabalho analisa a ideologia em alguns marcos legais da educação inclusiva, bem como no discurso de alguns professores acerca dessa proposta de Ensino. Ele busca, principalmente, entender as razões da resistência à execução da perspectiva inclusiva no ambiente escolar. Assim sendo, pretende-se aqui provocar uma reflexão sobre as dificuldades da implantação dessa proposta. Esta pesquisa se apoia na metodologia qualitativa, utilizando-se das teorias e dos métodos de Análise de Discurso Crítica de Fairclough (2001 e 2003), bem como da teoria sobre ideologia de Thompson (1995). Essas abordagens se entrelaçam e servem aqui como ponto de apoio para entender a elaboração e a interpretação do texto legal que fundamenta a educação inclusiva.

Palavras-chave: Ideologia. Discurso. Inclusão.

In this work, we analyze the Ideology present in some legal landmarks of the inclusive education and the discourse of some teachers about this perspective in Education. This work tries to understand the reasons of the resistance in the execution of the inclusive perspective. Thus being, when analyzing the present ideology in these legal texts is intended here to promote a reflection on the difficulties of the implantation of this proposal. This research is based on the qualitative methods and use the theories and the methods of analysis of the speech of Fairclough (2001 and 2003), as well as the theories on Ideology of Thompson (1995). These approaches interact and serve here as a support to understand the elaboration and the interpretation of the legal text that provides the foundations of the inclusive education.

Keywords: Ideology. Discourse. Inclusion.

\footnotetext{
${ }^{1}$ Mestre em Linguística pela UnB; membro do CEPADIC; desenvolve pesquisas em Análise de Discurso Crítica; $E$ mail: candiceassuncao@hotmail.com.
} 


\section{Introdução}

Neste trabalho, pretendemos analisar a ideologia presente em alguns marcos legais da educação inclusiva, antes e depois da Declaração de Salamanca, documento original dessa nova proposta educacional, que provocou uma mudança radical da educação no Brasil.

Fairclough é aqui utilizado, pois sua teoria descreve os efeitos do discurso. Ele assume o discurso como um elemento que ao mesmo tempo que molda a sociedade é moldado por esta. Assim, a sua perspectiva é analisar como a mudança social muda o discurso e ao mesmo tempo como o discurso transforma a prática social. A teoria de Fairclough é tanto linguisticamente, quanto socialmente orientada. Somam-se a esta perspectiva de trabalho as contribuições sobre ideologia apresentadas por Thompson (1995), cujo estudo permite sistematizar os meios como a ideologia se infiltra nos discursos e nas práticas sociais naturalizadas.

A educação inclusiva surge como consequência da luta pelo direito das pessoas com deficiência. Essa proposta educacional aparece como uma nova política de educação que foi vista, num primeiro momento, como uma inovação da educação especial, mas, progressivamente, expandiu-se em todo o contexto educativo, como uma tentativa de fazer com que a educação fosse de qualidade e que chegasse a todos.

Isso representou o rompimento de um paradigma que se centrava na ideia de integração das pessoas com deficiência na aproximação ao padrão de normalidade vigente. Isso significava que somente as pessoas com deficiência que se adequassem ao padrão exigido poderiam ser integradas e aceitas no ambiente escolar.

Essa perspectiva deu lugar a um outro paradigma, o da inclusão. Provocando uma mudança radical nas práticas socioeducativas, passou-se a ter agora como política de base o respeito à diferença. Tal mudança introduz uma nova ética, a ética da diversidade. Rompe-se, por extensão, a ideia de adaptabilidade das pessoas com deficiência ao status quo.

\section{Construção Histórica da Educação Inclusiva}

A educação inclusiva é o processo de inclusão de pessoas com deficiência na rede comum de ensino em todos os seus graus, da pré-escola ao ensino superior. Nessa proposta, a escola deve disponibilizar os meios necessários para o desenvolvimento das potencialidades humanas. Sua função não se restringe à educação escolar, mas abrange a formação da cidadania e até mesmo a construção do sujeito como um todo.

Ao se falar do processo de educação inclusiva, é necessário compreender, em primeiro lugar, que a inclusão não apareceu por acaso. Ela é um produto histórico da realidade 
contemporânea, que passou a exigir o abandono de antigos estereótipos e preconceitos. Como consequência disso, houve uma mudança social relativa à convivência com pessoas com deficiência, possibilitando uma ressignificação das práticas sociais. Durante a história da sociedade em geral, a prática social vigente não deu às pessoas com deficiência o direito de escrever a cidadania plena, ou seja, não foi lhes permitido acesso ao ensino regular, tampouco ao trabalho como atividades correntes do ser humano.

A história da educação inclusiva encontra raízes em outras áreas do conhecimento. Seus fundamentos se encontram em movimentos sociais anteriores à década de 60. Os eixos básicos da educação inclusiva se construíram com o enfeixamento de quatro fontes: a psicanálise, a luta pelos direitos humanos, a pedagogia institucional e o movimento de desinstitucionalização manicomial. Foram esses os desencadeadores que constataram o problema da exclusão social, que tomou outras formas e exigiu novas práticas educacionais e sociais. A Declaração de Salamanca, documento originário da Conferência Mundial sobre Necessidades Educativas Especiais, é a que, de maneira mais decisiva e explícita, tem contribuído a impulsionar a educação inclusiva em todo o mundo.

O Brasil, até o fim do século XIX, segregou totalmente as pessoas com deficiência. Somente no início do século XX surgiram as escolas especiais, nas quais as pessoas com deficiência poderiam estudar, mesmo assim, somente até o nível escolar que era ofertado por estas instituições. Na segunda metade do século XX, com o surgimento da integração, as pessoas com deficiência estudavam, inicialmente, nas escolas especiais, e, em seguida, eram integradas ao ensino regular. E isso só ocorria se o indivíduo conseguisse se adequar ao ritmo da escola regular e, por si só, pudesse se integrar à nova realidade.

Sem dúvida, algumas pessoas com deficiência conseguiram se adequar às exigências da educação regular, mas um número maior continuou segregado por não conseguir fazê-lo. Somente no fim da década de 90, o Brasil adota a educação inclusiva. Nessa perspectiva, é a escola que deve ser flexível e se adequar às necessidades do aluno. Essa nova política prometia eliminar a lógica da exclusão em nosso país, entretanto, essa proposta não foi largamente aceita no âmbito educacional. Isso decorre da falta de conhecimento, não somente por parte dos educadores, mas de toda a sociedade, inclusive os pais. Basta perguntar a qualquer pessoa e, com certeza, a maioria afirmará que a inclusão de pessoas com deficiência no ensino regular é algo inviável e que dela não poderá advir nenhum efeito positivo. Muitos, inclusive, atestariam que tal medida é sinônimo de atraso e de perturbação para os demais alunos.

Outra justificativa é a ideia de exclusão já naturalizada, segundo a qual os alunos com deficiência devem estudar em escolas separadas. No entanto, com a política de inclusão que vem sendo implantada, essa experiência vem se mostrando muito rica, seja em crescimento humano, 
profissional ou pessoal, para todos os envolvidos no processo. O professor, por exemplo, assumirá uma nova perspectiva, que valorizará as habilidades pessoais, as particularidades e as diferenças entre os indivíduos. Agindo assim, ela otimizará o potencial pessoal e, consequentemente, os demais alunos se beneficiarão igualmente com este processo.

A Análise de Discurso Crítica (ADC) busca a conscientização e o desvelamento, por meio dos quais é possível compreender a ideologia vigente e a transformação social. A ADC questiona como a ideologia se materializa no discurso e como o discurso reflete as práticas sociais, ao mesmo tempo em que exerce o papel de agente transformador da sociedade.

\section{Pressupostos Teóricos}

Fairclough (2001) apresenta os efeitos constitutivos do discurso. Ele aponta que o primeiro efeito consiste na ideia de que o discurso proporciona a construção das identidades sociais, posições de sujeito e os tipos de eu. O segundo efeito apontado é de que o discurso tem o papel de contribuir na construção das relações sociais entre as pessoas. No terceiro efeito, o discurso contribui para a construção de sistemas de conhecimento e crença.

Após indicar os efeitos constitutivos do discurso, Fairclough segue afirmando que tais efeitos correspondem, respectivamente, a três funções da linguagem, as quais o teórico em questão denomina: funções da linguagem identitária, relacional e ideacional. A função identitária refere-se ao modo pelo qual as identidades sociais são estabelecidas no discurso; a função relacional refere-se à maneira pela qual as relações sociais entre os participantes do discurso são representadas e negociadas; e a função ideacional relaciona-se a forma pelo qual os textos representam a sociedade de modo geral. Ressaltamos que este trabalho tem como ponto de base a função ideacional, pois é por meio dela que poderemos antever como a sociedade assimila o discurso da educação inclusiva e como o discurso pode contribuir na mudança social, perspectiva essa pretendida pela educação inclusiva.

Compreender a dimensão do termo "discurso" nos remete aos objetivos da teoria da Análise de Discurso Crítica, pois toda análise fundamentada na ADC tem como ponto de partida um problema existente que se firma nas relações de poder, na desigualdade da distribuição material e simbólica e na naturalização de discursos particulares como sendo universais. Assim, a ADC visa, primordialmente, desvelar o que está oculto no discurso e nas práticas sociais e provocar uma mudança discursiva e social devido ao caráter crítico da teoria. Com isso, é um instrumento que ajuda a esclarecer e a eliminar o preconceito e a resistência social que a proposta de educação inclusiva tem encontrado. 
Segundo Thompson (1995), não se deve derivar dos fenômenos simbólicos puramente a ideologia, mas deve-se compreender que os fenômenos simbólicos podem estar, ou não, investidos ideologicamente. A posição de Fairclough (2001) é semelhante à de Thompson, pois ambos entendem a linguagem como um meio possível de estabelecer, de manter e de sustentar as relações de dominação. Isso é possível graças ao processo de naturalização, que torna senso comum as ideologias embutidas nas práticas discursivas.

\section{Metodologia e análise dos textos legais}

Nesta análise, utilizaremos a pesquisa qualitativa, pois ela é o método que mais se adequa a um estudo social. Esse método dá preferência à representação das realidades sociais e evita os números, possibilitando a prática de pesquisa crítica e emancipatória.

Somam-se a esta perspectiva, as contribuições de Fairclough, que organiza a análise textual nos itens vocabulário, gramática, coesão e estrutura, já utilizados pela tradição da análise textual. O teórico acrescenta mais três categorias, que segundo ele, são usados na análise da prática discursiva: a força dos enunciados, a coerência dos textos e a intertextualidade.

Fairclough (2003) postula que não se deve apenas estar interessado somente nos textos, mas também no processo interativo de produção de significado. De suas várias categorias apresentadas, ressalta-se, neste trabalho, a racionalização, processo de legitimação que age por meio da utilidade da ação institucionalizada, ou seja, é a sociedade de conhecimento construída que dota a ideologia de validade cognitiva. Por exemplo, o art. 206 da Constituição Federal do Brasil, 1988, inciso I diz que "O ensino será ministrado com base nos seguintes princípios: igualdade de condições para o acesso e permanência na escola".

Tal inciso foi interpretado na ideia geral de exclusão, segundo a qual deveria haver escolas especiais para alunos com deficiência. No entanto, com o advento do movimento de inclusão que vem, aos poucos, promovendo uma mudança social, o mesmo inciso é lido de forma a indicar que a escola regular é que deve dar acesso e permanência a todos os alunos, independentemente de suas condições físicas. Nota-se, portanto, o quanto o texto está sujeito a diversas interpretações e como, por meio do processo de legitimação por racionalização, a interpretação naturalizada forma o pensamento ideológico social.

Implicitamente se encontra ainda a legitimação por mythpoesis, relatada por Fairclough (2003) como a legitimação na forma de narrativa. É importante ressaltar que, embora não seja a rigor uma narrativa, esse trecho específico da Constituição Federal cria uma "cena ideal", 
fazendo-nos crer que bastava garantir a existência de escolas especiais que estava garantido o direito de igualdade.

Vejamos agora outro trecho da CF de 1988, art. 208, inciso III, segundo o qual o "dever do Estado com a educação será efetivado mediante a garantia de: atendimento educacional especializado aos portadores de deficiência, preferencialmente na rede regular de ensino".

No momento histórico em que ocorreu a promulgação da Constituição, o Brasil vivia em pleno momento de integração, portanto o atendimento educacional especializado era sinônimo de escola especial. Esse inciso foi interpretado como que a escola regular deveria apenas assimilar as pessoas com deficiência que pudessem, por si só, ter condições de acompanhar os outros alunos. O termo 'preferencialmente' deu margem à interpretação de que, se não fosse possível tal integração, que a pessoa com deficiência buscasse o ensino especial.

Contudo, agora no novo contexto de inclusão, quase 20 anos depois, a leitura dessa passagem é outra, uma vez que, agora, esse atendimento especializado é visto como um complemento da educação, ou seja, o apoio necessário para que o aluno acompanhe o ensino regular, com independência e autonomia. $\mathrm{O}$ atendimento educacional especializado não é mais entendido como escolarização plena, pois a educação, em seu sentido pleno, só pode ser oferecida na rede regular de ensino.

Essa leitura não foi feita durante muito tempo devido à ideologia vigente na época calcada na lógica da exclusão. Thompson (1995) conceitua esse processo como ideologia sustentada na legitimação por racionalização. Aqui, a ideologia se materializa por meio de uma cadeia de raciocínios que sustenta um conjunto de relações, levando a crer que são dignas de apoio. Essa foi a ideologia que se escondia por detrás da primeira leitura, criando uma ideia de que existe uma escola especial que poderia substituir o ensino regular. Thompson (1995) apresenta outra categoria de análise que, em particular, se aplica a este enxerto da CF de 1988: a fragmentação por meio da diferenciação. Segundo Thompson, a fragmentação é um modo de operação que dita que as relações de dominação podem ser mantidas não unificando as pessoas numa coletividade, mas segmentando e repartindo as pessoas em grupos. A diferenciação ocorre quando é dada uma ênfase às distinções apoiando as características que desunem, em detrimento de uma identificação mais abrangente. A fragmentação aqui se ilustra quando o inciso dá margem para interpretar que, quando não for possível o engajamento no ensino regular, uma escola especial deveria ser o destino do aluno com deficiência. Ao ressaltar a diferença entre os alunos, esta forma de legitimação da ideologia causa a exclusão social, que não se restringe somente à escola, mas que, partindo dela, alastra-se por todas as instituições sociais.

Fairclough (2001) postula também a relexicalização dos domínios da experiência como parte de lutas sociais e políticas que, travadas externamente, perpassam a linguagem. Um 
exemplo neste mesmo inciso é o atendimento educacional especializado, que antes era interpretado num sentido de exclusão, sinônimo de ensino especial. Contudo, decorrida a relexicalização dessa passagem, no momento atual, tem-se o ensino especial não mais como um substituto do ensino regular, mas apenas sua complementação.

Entre os itens de análise de Fairclough (2001), esclarecem-se, agora, os efeitos que a gramática pode ter nas implicações de sentido do texto. A voz passiva, por exemplo, utilizada no texto constitucional, oferece o apagamento do agente, deixando, segundo Fairclough (2001:105) vaga a agência e, consequentemente, vaga a responsabilidade.

A Lei 9394/96 (LDB), art. 58, § 2º, diz que o "atendimento educacional será feito em classes, escolas ou serviços especializados, sempre que, em função das condições específicas dos alunos, não for possível a sua integração nas classes comuns de ensino regular". Como ilustrado acima, podemos constatar que o texto apresentado, base das diretrizes educacionais, evidencia cada vez mais a exclusão social na sala de aula. Olhando a sua estrutura, podemos notar que há uma ênfase no atendimento especializado fora do ensino regular. A hipótese do ensino regular aparece no último plano da estrutura textual, praticamente oculta. No caput do artigo, o texto entra em intertextualidade com a constituição, mas, agora, há uma associação direta entre atendimento educacional especializado e ensino especial. Eles são vistos como sinônimos e isso, mais uma vez, reforça a ideia de exclusão, noticiando que existe "um outro lugar" para pessoas com deficiência.

Em uma primeira leitura, o que se lê é que o atendimento educacional especializado em classe e escola segregada seria a regra, graças à topicalização que este termo recebeu na oração e, somente como último termo da oração, aparece a possibilidade do ensino regular. A expressão "quando não for possível" nos traz a percepção de que a impossibilidade é a regra, e não o seu contrário. A ênfase aqui é na capacidade pessoal de cada um, deixando o contexto social, inclusive o poder público, isento de sua parcela de responsabilidade sobre a questão.

Thompson trataria da ideologia presente nesse parágrafo como uma estratégia de dissimulação por meio de eufemização, ou seja, o processo de desvio da nossa atenção, passando por cima de processos e de situações existentes. A mesma expressão "quando não for possível” é o que mascara a ideia expressa em intertextualidade velada, já indicada nos outros textos, de que é encargo do aluno a sua integração efetiva. O pensamento ideológico completa-se ao haver, por meio da eufemização, uma valorização da escola especial, que foi reescrito como "em classes, escolas ou serviços especializados".

A negação presente no termo chama a atenção para uma segunda voz, que diz que a Inclusão pode ser possível. Assim, a ênfase na negação tentaria calar a voz da resistência. Segundo Fairclough (2003), a negação implica que a asserção está em 'outro lugar' daquilo que 
está sendo negado. A ordem discursiva de inclusão que se apresentava no mundo naquela época começa já a ser pensada, mas de forma ainda bastante sutil, dentro do contexto educacional.

Thompson (1995) fala sobre o processo de reificação como a alavanca de conservação da ideologia, já que é uma construção histórica uma pessoa com deficiência ser educada em uma escola especial, ou seja, aquilo que é estabelecido no curso sócio-histórico se tornou algo natural e atemporal dentro das práticas sociais.

Na nova visão inclusiva, o artigo 58 é lido como que o que pode ser ofertado em escolas e em classes especiais é o atendimento educacional especializado, ou seja, o complemento necessário para que o aluno com deficiência siga junto com os demais alunos e, mais uma vez, não como um substituto do ensino regular.

Vejamos, agora, a Lei 7.853/1989, art.2º $§$ Único, inciso I, alínea f:

A matrícula compulsória em cursos regulares de estabelecimentos públicos e particulares de pessoas portadoras de deficiência capazes de se integrarem no sistema regular de ensino.

Pode-se inferir aqui as suposições existencial e moral, como propõe Fairclough (2003). A primeira é aquela suposição que diz que algo já existe, tomando isso como natural. Ao trabalhar o inciso, nota-se que ele afirma que a escola regular deve garantir a matrícula compulsória para os capazes de se integrar e tem como suposição a existência das escolas especiais para aqueles alunos que não são capazes de se adequar aos padrões exigidos na escola.

A segunda suposição, a moral, trata daquilo que é tido como bom e desejável. A expressão "capazes de se integrar" remete à ideia de que ensino regular é bom para quem tem condições para nele permanecer. A suposição é que, para quem não condiz com essas exigências, a escola regular não é o mais desejável. Nota-se que tal assertiva também é boa para a escola, na qual seus alunos serão somente aqueles capazes de se integrar.

Tudo isso nos leva a compreender que a suposição é uma ferramenta da ideologia e que ela é usada, nesse caso, para seccionar e excluir os sujeitos. Há uma outra voz no discurso, que é a fala da sociedade reforçando a ideia da escola segregadora.

A própria estrutura gramatical nos remete ao exposto sobre a suposição. Infere-se, de acordo com Fairclough (2003), a escolha semântica do condicional, implicando que, para se integrar ao ensino regular, é necessário que haja a condição ulterior de autocapacidade. Ressaltase que esse caráter estrutural do texto jurídico ilustra que a exclusão não está só no conteúdo da sociedade, mas é parte da sua própria estrutura, como é parte da estrutura do texto. 
O Decreto 3298/1999 estabelece intertextualidade com a Lei 7853/89. Assim, a análise que se aplica lá se aplica aqui também. No entanto, chama-se a atenção, neste momento, a ferramenta da ideologia que ocorre por reificação por meio da naturalização. Segundo Thompson (1995), a naturalização é o procedimento de que um estado de coisas que foi criado historicamente passa a ser tratado como um acontecimento natural. É esse procedimento que faz colocar a pessoa com deficiência na escola especial, dando ênfase às condições físicas do aluno, colocando nele as barreiras à inclusão escolar, ao usar a expressão "capaz de se integrar", no inciso I, segundo o qual a "A matrícula compulsória em cursos regulares de estabelecimentos públicos e particulares de pessoa portadora de deficiência capazes de se integrar na rede regular de ensino".

A intertextualidade com a Lei 7853/89 revela que houve um retrocesso. A mesma voz da resistência que apareceu sutilmente na LDBEN e foi reprimida na citada lei foi novamente suprimida, aqui, no decreto. Contudo, essa 'montanha russa' das perspectivas educacionais é o reflexo da luta social entremeada no discurso, pois em qualquer luta há retrocessos e ganhos. Infelizmente, por enquanto, o discurso da exclusão era o vitorioso. Destacam-se, portanto, as datas dos textos, em que 10 anos depois da publicação da Lei 7853/89 no decreto listado, há o retorno para o passado de exclusão.

Entretanto, a reinterpretação de ambos os ordenamentos jurídicos, tanto a Lei 7853/89, como o Decreto 3298/99 que regula essa lei, recai sobre a expressão "capaz de", que é lida agora como referência às pessoas com total impossibilidade de interação com o meio externo, como as pessoas em estado vegetativo ou com sérios problemas de saúde. Não se refere mais às pessoas com deficiência que são capazes de interagir ou ao público que está matriculado nas escolas especiais.

Tais pessoas são citadas para que haja a garantia de que, caso ocorra uma melhora, mesmo que ínfima, dessa condição de saúde, esses alunos, por direito e por lhes ser mais proveitoso e desafiador, deverão freqüentar escolas comuns da rede regular (FÁVERO, 2007).

Em 2001, o discurso da resistência ganhou mais força, pois, pela primeira vez, aparece o termo inclusão em alguma legislação no Plano Nacional de Educação (PNE), embora ainda ele seja sinônimo de integração. São os primeiros sinais de uma nova ordem discursiva para os primeiros passos de uma nova ordem social. Agora, nesse texto, já ocorre uma inversão da topicalização apontada anteriormente. Nele, já se nota a topicalização do termo "escola regular", reforçando a tese de que a estrutura gramatical do texto não é aleatória, mas, pelo contrário, intencional, seja nas suas escolhas lexicais, gramaticais, seja mesmo da ordem das palavras.

Assim é que o discurso da resistência ganha mais força no meio social, e tal força pode se evidenciar no texto. Veja o anexo do PNE presente em Lei 10172/2001, item 8 - Educação 
Especial subitem 8.1 - diagnóstico. De acordo com esse anexo, as tendências recentes dos sistemas de ensino são as seguintes: "integração/Inclusão do aluno com necessidades especiais no sistema regular de ensino e, se isto não for possível em função das necessidades do educando, realizar o atendimento em classes e escolas especializadas”.

Apesar desse avanço demonstrado no texto supracitado, ainda se abre possibilidade de a escola especial, mas ainda de uma forma velada, coloca o encargo do sucesso escolar sobre os ombros do aluno, enfatizando a responsabilidade pessoal. Isso se enquadra na operação da ideologia da dissimulação por meio da eufemização, como dito anteriormente. Ainda se naturaliza o fato de que o fracasso escolar da pessoa com deficiência se interconecta com as suas condições físicas. Mais uma vez, a ideologia opera por meio da reificação por naturalização, como defende Thompson (1995).

Nota-se que o movimento de tornar inclusão semelhante à integração dentro do texto provoca um reforço sobre essa perspectiva educacional, pois, como se atesta mais adiante, há o predomínio do termo “integração" em detrimento do termo “inclusão". Pode-se perguntar também porque aparece primeiramente integração e não inclusão, pois, mais uma vez, ele topicaliza a integração, ao mesmo tempo em que coloca como sinônimos as duas palavras, revelando o apagamento da proposta de inclusão.

Outro ponto significativo nesse texto é a mudança nas práticas sociais dentro das escolas ao indicar todas as transformações por que elas devem passar, de acordo com o PNE. No entanto, é algo contraditório, pois mesmo com a visão de avanço presente aqui, o texto ainda retoma aspectos do ensino especializado, como visto em décadas passadas. Essa ambiguidade é, pois, uma amostra positiva de que o discurso do excluído alcança o discurso do poder, tanto que, neste último, transparece essa questão, sendo confusa e aberta a várias interpretações.

Se esse texto for lido na visão dos defensores da inclusão, haverá uma tônica sobre a transformação da escola, enquanto que, se for lido na ótica contrária à inclusão, o foco será no pressuposto da limitação, aqui expresso textualmente como "necessidade educacional especial".

Observemos, agora, a construção ideológica que a Resolução CNE/CEB/2011, art. 7, faz em relação à educação inclusiva, ao dizer que o "atendimento aos alunos com necessidades educacionais especiais deve ser realizado em classes comuns do Ensino Regular, em qualquer etapa ou modalidade da Educação Básica”.

Esse artigo ilustra a visão educativa pautada na inclusão de uma forma que não exclui e não gera ambiguidade de sentido, pois não dá margem à interpretação corrente de que o lugar do aluno com deficiência, que não consegue por si só acompanhar a escola regular, é a escola especial. Ao contrário, ele enfatiza que esse atendimento necessário deveria ser em classes comuns. O artigo nem usa o termo "atendimento educacional especializado" para evitar esse tipo 
de interpretação. Assim, ao colocar o termo "apoio ao aluno", o artigo desmistifica o atendimento educacional, colocando o aluno como algo importante para a estrutura da educação.

No entanto, o artigo $9^{\circ}$ afirma que as "escolas podem criar, extraordinariamente, classes especiais, cuja organização fundamenta-se no Capítulo II da LDBEN, nas diretrizes curriculares nacionais para a Educação Básica, bem como nos referenciais e parâmetros curriculares nacionais, para atendimento, em caráter transitório, a alunos que apresentem dificuldades acentuadas de aprendizagem ou condições de comunicação e sinalização diferenciadas dos demais alunos e demandem ajudas e apoios intensos e contínuos”.

Este artigo, contudo, provoca uma desconstrução da ideia apresentada no artigo anterior, pois já abre a possibilidade a uma classe especial, tendo em vista que, mesmo que enfatize o caráter transitório, diz que esse aluno terá apoio intenso e contínuo. Ora, se é transitório não pode ser contínuo, ou, em outras palavras, se ele deve estar na classe especial por algum período devido às suas limitações físicas contínuas, quando que ele não precisará mais desse apoio?

Outra questão é que esse artigo abre espaço para que todos os alunos com deficiência, independentemente de sua limitação, sejam encaminhados para uma classe especial. $\mathrm{O}$ artigo, mais uma vez, foca a diferença que expurga e discrimina o outro, em vez de valorizar a diferença como uma característica inerente do ser humano. Falta, aqui, a percepção de que a escola é a instituição que segrega, por não oferecer os instrumentos necessários para que as pessoas, deficientes ou não, sejam desenvolvidas plenamente em todo o seu potencial humano.

Finalmente, o artigo $10^{\circ}$ diz que os "os alunos que apresentem necessidades educacionais especiais e requeiram atenção individualizada nas atividades da vida autônoma e social, recursos, ajudas e apoios intensos e contínuos, bem como adaptações curriculares tão significativas que a escola comum não consiga prover, podem ser atendidos, em caráter extraordinário, em Escolas Especiais, públicas ou privadas, atendimento esse complementado, sempre que necessário e de maneira articulada, por serviços das áreas de Saúde, Trabalho e Assistência Social”.

Apesar de tentar mascarar a questão da incapacidade latente de acompanhar o ensino regular, como se essa fosse presente no aluno e não no sistema educacional, o artigo acaba por ser um retrocesso histórico na luta pela inclusão, porque, mais uma vez, ele legitima a escola especial.

O mais interessante aqui é a construção que tenta exagerar as condições físicas da pessoa com deficiência, construindo uma imagem de dificuldade intensa e insuperável, em que o aluno com deficiência se torna o sujeito que somente gera entrave dentro do ambiente escolar, de tal forma que ela não consegue atendê-lo. O artigo termina, por fim, tentando fazer uma compensação material (serviços das áreas de Saúde, Trabalho e Assistência Social) que tenta se sobrepor ao seu direito à educação. Mais do que nunca o que dita a exclusão novamente é a 
condição física, topicaliza na oração, como resistência ao discurso da inclusão, demonstrando que, apesar do mascaramento, este discurso não se efetivou como ordem social.

Utilizando as categorias de análise da ideologia de Thompson (1995), pode-se inferir que, na legitimação de racionalização, uma forma simbólica é construída como uma cadeia de raciocínio que protege e legaliza um conjunto de relações, na tentativa de persuasão sobre o que é mais ou menos partilhado como digno de apoio. O raciocínio construído é o de que a escola regular está aberta às pessoas com deficiência e que são elas que não conseguem se adaptar ao ambiente escolar, retirando, assim, a culpa do sistema público como otimizador do acesso e da permanência do aluno com deficiência.

Continuam outras categorias de analise da ideologia, tais como a diferenciação pela fragmentação e a reificação por meio da naturalização. As mesmas ferramentas da ideologia presentes em outros textos ainda se fazem valer aqui, mesmo que disfarçadas.

O artigo $1^{\circ}$, inciso I, da Lei 10.845/2004, acima destacado, que institui o Programa de Complementação ao Atendimento Educacional Especializado às Pessoas com deficiência (PAED), diz que se deve "garantir a universalização do atendimento especializado de educandos portadores de deficiência cuja situação não permita a integração em classes comuns de Ensino Regular".

Aqui, ocorre a tentativa de propor uma melhoria no atendimento educacional especializado, mas, contrariamente, acaba por reforçar a ideia contida nos outros ordenamentos legais, pois, apesar de criar um programa específico para esses alunos, foca sua ação naqueles que não puderam ser incluídos no ensino regular, pressupondo, portanto, que eles deveriam ser educados e atendidos em espaço outro que não a escola regular.

Chama-se a atenção para o fato do reaparecimento do termo "integração" em detrimento do termo "inclusão", evidenciando o pensamento social de que a escola não é para todos. O uso da expressão "Cuja situação não permita" é uma tentativa de mascarar o termo corrente "capaz de", uma vez que, no campo semântico, ambos são interpretados no mesmo sentido de exclusão ainda com base nas condições físicas dos alunos. Apresenta-se, aqui, uma afirmação hipotética que implica ação excludente ao abrir a hipótese de que o aluno em questão deveria ir para uma escola especial, caso não conseguisse acompanhar o ensino regular.

Das ferramentas de que a ideologia se reveste, como em todos os trechos analisados, verifica-se mais uma vez a dissimulação por meio da fragmentação e a reificação por meio da naturalização, ambos processos já explicados anteriormente.

A releitura de todos os textos que veem a educação especial simplesmente como um suplemento ao ensino regular é feita para que tais aparatos legais não sejam totalmente invalidados e, ao mesmo tempo, eles não invalidem a proposta de inclusão, mas, pelo contrário, 
dado ao seu poder jurídico na educação, eles sejam um aliado na luta contra o preconceito e a desinformação. No entanto, apesar dessa releitura, eles ainda deixam transparecer a ideologia de exclusão, seja em sua estrutura textual, seja por meio da escolha do léxico.

Todas estas questões são pertinentes e ilustram a permanência da tradição naturalizada da exclusão. Comprovando isso, podemos utilizar as teorias de Thompson, que nos dão a ideia dos modos de legitimação, acrescidas das categorias de Fairclough, ambos nos mostrando como o texto ajuda a sustentar a ideologia vigente.

\section{Metodologia e análise das entrevistas com professores}

As entrevistas deste trabalho foram realizadas em duas escolas públicas da periferia da cidade de Anápolis - GO. A primeira é Municipal e trabalha somente com Ensino Fundamental, e a segunda é Estadual e trabalha tanto com Ensino Fundamental, quanto com Médio e Educação de Jovens e Adultos.

No total, ocorreram duas entrevistas grupais com professores. Na primeira escola, o grupo entrevistado era composto de dez professores do Ensino Fundamental. Na segunda, a entrevista ocorreu com sete professores da EJA. Todos se mostraram receptivos à entrevista e se sentiram motivados a falar, embora tenha ocorrido o monopólio da fala por alguns deles. Ambas as escolas vivenciam, agora, a proposta inclusiva, mas não possuem ainda bons resultados no momento.

As entrevistas fizeram-se necessárias aqui para percebermos como essa nova proposta está sendo vista pelo docente, ao mesmo tempo em que se quer perceber como está acontecendo o processo de efetivação da inclusão nas escolas, tendo como arcabouço teórico as propostas de análises de Fairclough (2003) e de Thompson (1995). O que se intenta saber é como estaria o início de implantação de uma nova ordem social, tentando perceber como isso está se dando, entendendo, ao mesmo tempo, as ideologias naturalizadas em seus procedimentos e como o discurso pode nos revelar essa ideologia e seus preconceitos. 


\section{Entrevista A}

A escola escolhida para essa entrevista foi pública, pois o processo de inclusão ganha mais relevância nessas entidades. Priorizou-se uma escola de periferia, por tratar de perceber como andam essas reflexões em nichos sociais mais afastados do centro econômico.

A entrevista ocorreu em escola municipal com um grupo composto por professores de várias classes do Ensino Fundamental, mesmo que nem todos tenham se disponibilizado para expressar suas opiniões. No entanto, daqueles que falaram, depreende-se que as ideias veiculadas por meio deles eram partilhadas pela maioria do grupo. Percebeu-se que as percepções são instigantes e até mesmo contraditórias quando o assunto é inclusão como, por exemplo, questões como falta de conhecimento, até mesmo preconceitos velados.

$\mathrm{Na}$ primeira entrevista, percebe-se apelo afetivo por parte dos professores, chamando a atenção para fatos de humanização, no entanto, entremeada a isso, encontrava-se a consciência geral de que a inclusão não gerava nada de positivo para o processo educativo. Nota-se o escape nas falas que sempre remetem a dificuldades de formação dos professores, aliadas a um sentimento geral de impotência e de resistência frente à proposta inclusiva. Inicialmente, o professor entrevistado diz que na, prática efetiva, o processo de inclusão não acontece, pois, segundo ele, "é muito difícil trabalhar com dois grupos ao mesmo tempo"2. Ou seja, isso ilustra já a própria falta de consciência do que seja realmente a perspectiva de inclusão, uma vez que a inclusão fala sempre em apenas um grupo heterogêneo.

Essa visão docente deixa transparecer, à luz das categorias de análise da ideologia de Thompson (1995), um processo de fragmentação, uma vez que se mantém a perspectiva de escola especial, na medida em que se criam dois grupos. Na verdade, o que houve foi o apagamento da segregação do espaço físico, sem, contudo, efetivar o processo de inclusão. Não há mais uma escola separada, nem uma sala de aula especial, mas há, assim, um grupo segregado dentro da mesma sala de aula.

É importante chamar a atenção para os diferentes graus de consciência sobre a permanência da exclusão na tentativa da inclusão em sala de aula. Nota-se, entre os professores, uma certa visão dualizada, uma mão dupla ditando que deve haver, por exemplo, atividades diferenciadas, mas que propiciem, cada uma à sua maneira, a inclusão e a aprendizagem. Contudo, seja por despreparo, seja pela ideologia internalizada da diferença, o professor não otimiza o processo de ensino aprendizagem por meio dessas atividades, mesmo tendo noção de que está excluindo e separando seus alunos. Nas falas:

\footnotetext{
${ }^{2}$ Informação verbal.
} 
Você não pode diferenciar um deficiente de um normal porque você está excluindo, mas você tem que dar um atendimento diferente porque talvez ele não aprenda da mesma forma que um outro. Talvez não, ele não aprende (...) porque tem que ter uma forma diferente de atender, mas também tem que ter uma forma igual de atender, porque senão eu estou excluindo. ${ }^{3}$

Está presente aqui uma crescente modalização do discurso, fazendo crer que é praticamente impossível a concretização da inclusão. Para os docentes, é sempre muito difícil, é sempre muito complicado. Segundo Halliday (apud FAIRCLOUGH, 2003), a modalidade é o julgamento do falante quanto às probabilidades ou obrigações concernentes ao que ele diz. A modalidade é o que consegue fazer a mediação entre o falante e suas representações, ditando os níveis de afinidade e de compromisso, as suas incertezas, suas necessidades e até mesmo as suas permissões ou obrigações em que o falante está inserido.

Assim, nessa representação de mundo, o falante pode fazer uma avaliação de valor. Segundo Fairclough (2003), esse processo de avaliação pode ocorrer por meio de advérbios, de adjetivos e até mesmo de verbos. Aqui, o juízo de valor se encontra no advérbio ("muito"), construindo o raciocínio de que essa proposta é praticamente inviável. Essa avaliação de valor é feita por meio de uma afirmação real (FAIRCLOUGH, 2003), que acaba por assegurar que a dificuldade existe de fato, não é uma hipótese e que tal dificuldade se concretiza na existência de grupos distintos na mesma classe.

O docente confirma essa ideia de modalização de valor real ao afirmar que "com certeza" se sentiria impotente diante de um "aluno diferente". Para Fairclough (2003), este advérbio traz consigo um nível de envolvimento de verdade alta, indicando que trabalhar com alunos com deficiência é muito difícil e que esta percepção é tida como algo que não abre qualquer tipo de dúvida.

Tamanha certeza se dilui um pouco quando o docente fala o que "acha", em relação às vantagens que a pessoa "dita normal realmente ensina para o outro (pessoa com deficiência)" . Ao usar este termo, modaliza-se a oração para que haja menos envolvimento dele como falante no tocante à questão da aprendizagem inclusiva.

É importante ressaltar que, ao indicar pontos negativos da educação inclusiva, há o envolvimento na fala, de modo explícito, por parte do falante, querendo deixar bem marcada sua posição contrária à inclusão. No entanto, se há a necessidade de apontar pontos positivos, o falante, por outro ângulo, tenta ao máximo eximir-se de uma abordagem que indique realidade concreta e certeza de que a perspectiva inclusiva possa ocorrer efetivamente de maneira positiva.

\footnotetext{
${ }^{3}$ Informação verbal.

${ }^{4}$ Informação verbal.
} 
Outro ponto que merece atenção nesta análise da entrevista é o uso dos termos "diferente" e "deficiente". O entrevistado tem a constante preocupação em se corrigir, utilizando o primeiro termo em substituição ao segundo, pois, na sua opinião, o termo "deficiente" é pejorativo e comprometedor. O docente policia-se por medo de ser preconceituoso e, assim acaba por revelar implicitamente uma certa rejeição pessoal em trabalhar com alunos com deficiência.

Contudo, durante toda a entrevista, houve a construção de um conjunto de ideias que tentaram fundamentar e refinar a premissa de que a escola regular não é o local ideal para as pessoas com deficiência. Nessa busca de argumentos, há uma constante transferência de responsabilidade do seu próprio domínio de atuação como professor para outros domínios como a infraestrutura e as possíveis barreiras naturais que os alunos com deficiência possam ter, numa tentativa de mascarar seu próprio preconceito. Essas possíveis barreiras são, na sua visão, intransponíveis e insuperáveis, até o extremo de indicar que uma pessoa com síndrome de down “já traz a barreira na face, pois a face deles é um pouquinho diferente dos outros". . Nota-se a modalização "pouquinho" que tenta abrandar sua rejeição, ao mesmo tempo em que a evidencia.

Identificam-se, nessas atitudes, certas categorias de análise de ideologia de Thompson (1995), como a legitimação por meio da racionalização e da fragmentação por diferenciação (ambas já explicadas anteriormente). A mais evidente é a reificação por meio da naturalização, que, como já foi dito, estabelece a ideia de que algo construído historicamente é tido como natural, colocando a barreira na pessoa com deficiência, que é naturalmente um problema, e não no seu meio ou nas ideologias das pessoas que a cercam.

Outra categoria que se apresenta mais adiante é a fragmentação por expurgo do outro. Essa é aquela ferramenta da ideologia que cria um inimigo, que é retratado como mau, perigoso e ameaçador. O docente, ao dizer que "o aluno deficiente é agitado, toma as coisas dos colegas, não acompanha as atividades e perturba" acrescentando que "ele comia a massinha (...), ele comia aquelas bolinhas (de papel), comia as pontas dos lápis tudo",6 constrói um imaginário de discordância desse aluno para com a sala de aula, sendo ele o ponto de desajuste e que precisa ser afastado sob pena de prejudicar os demais alunos.

Sem dúvida, a situação enfrentada pelo professor é digna de atenção, mas não se pode colocar a culpa dessa situação no aluno. A vivência de uma proposta inclusiva possibilitaria a busca de meios e de recursos para modificar essa realidade, muito antes de simplesmente apontá-lo com elemento deletério na sala de aula. Ressalta-se aqui que, no modelo da prática social vigente, realmente este aluno é incompatível com a proposta de inclusão. Contudo,

\footnotetext{
${ }^{5}$ Informação verbal.

${ }^{6}$ Informação verbal.
} 
reforça-se que a solução não seria excluir o aluno, mas transformar a prática social, como, por exemplo, eliminando todos os tipos de barreiras, seja físicas, emocionais ou comunicativas.

Sobre o artigo da constituição, houve a interpretação inversa da interpretação feita pela proposta de inclusão. Fairclough (2001) ressalta que as interpretações sofrem variações de acordo com o grupo social que faz a leitura. Isso indica que a leitura que este grupo de professores faz é a aquela pautada na ideia de integração, quando eles dizem que "enquanto tiver condições aqui (escola regular) ele fica, depois tem que mudar"7, ou seja, o aluno é que deve se adaptar por mérito e não a escola que deve-se equiparar para melhor receber e educar o aluno com deficiência.

\section{Entrevista B}

O primeiro ponto a ser analisado nesta entrevista é o reforço por meio de modalizadores e o comprometimento com o que o falante acredita ou não. Em um primeiro momento, o docente usa a expressão “eu acho” para dizer que "a questão da inclusão está bem evidente em todos os segmentos", mas utiliza a expressão "eu vejo" quando afirma que a inclusão é utópica. Novamente, ao dizer algo positivo, não há a comprometimento; ao se negativizar, há maior comprometimento do entrevistado com seu ponto de vista. Ao justificar esse segundo ponto de vista, segue afirmando que "não é fácil trabalhar e atender uma clientela que precisa de necessidades especiais" ${ }^{8}$, em um movimento de negação a um outro discurso implícito que diz que é possível a inclusão.

Isso revela que este é um momento de transição que abala as práticas sociais vigentes e demonstra que o discurso da inclusão está, no mínimo, provocando uma reflexão que se evidencia pela presença implícita dele entremeado à ideologia do discurso que o nega. Um exemplo é o contraditório entre uma postura que diz que acha possível a inclusão, mesmo que nessa assertiva não haja grandes comprometimentos sobre a questão, mas que acaba por se aliar logo ao seu contrário, ao ser dito, mais à frente, que a "situação é muito difícil".9.

No trecho "eu concordo com ela (...), mas o ensino especial ficava melhor"10, há a concordância, em linhas gerais, com o que foi dito anteriormente, mas, ao mesmo tempo, há a negação de tudo, ao ser afirmado que o ensino especial é a melhor opção. Alia-se a isso a carga semântica de oposição fortemente marcada pela conjunção "mas" no mesmo trecho.

\footnotetext{
${ }^{7}$ Informação verbal.

${ }^{8}$ Informação verbal.

${ }^{9}$ Informação verbal.

${ }^{10}$ Informação verbal.
} 
No trecho "agora, com a ideia mais ampla precisava de mais recursos na escola, para o professor também" "11, é interessante perceber o movimento textual que passa a questão da educação inclusiva de uma necessidade de especialização para uma necessidade de recurso, ou seja, financeira, inclusive para os professores, trazendo uma ideia de premiação necessária para o docente. Essa necessidade fica evidente no termo "precisava” que, segundo Fairclough (2003), implica nível de obrigação alto, transparecendo a ideia de que é algo imprescindível.

Ressalta-se que, para que haja inclusão escolar, é importante que haja investimento financeiro que possa sanar os problemas de infraestrutura das escolas, por exemplo. No entanto, fixar-se apenas nas necessidades de recursos financeiros acaba por desprezar as implicações sociais presentes na questão, deslocando, assim, o envolvimento das ideologias internalizadas nos membros da sociedade, em uma tentativa de barrar o processo de inclusão.

Tudo isso culmina na percepção de que há uma luta entre o discurso favorável ao processo de inclusão e o discurso que o nega e contra ele resiste, afirmando que, sem sombra de dúvida, o momento de transição fica mais evidente. O docente contradiz tudo o que foi dito anteriormente ao afirmar que a escola especial não deve substituir a escola regular, mas, sim, que ambas "têm que caminhar junto", numa clara alusão à perspectiva inclusiva, contrária à perspectiva de integração anteriormente evidenciada. Alguma ideia já foi internalizada, mesmo que ainda dominada pela ideologia instaurada no meio social.

Mais uma vez, o tom de certeza modaliza-se em nível de envolvimento alto, deixando clara a posição pessoal de que a dificuldade é real. A ideia da dificuldade é outro entrave para a proposta de inclusão, pois as barreiras levantadas encontram-se intrínsecas na prática do professor. Assim sendo, é como se o processo de inclusão somente viesse para perturbar o bom andamento do trabalho docente.

Seguindo a entrevista, ao falar das vantagens e das desvantagens da inclusão, pode-se depreender questões dialógicas e intertextuais. Isso se percebe nas sucessivas afirmações enfáticas de que "somos todos seres humanos, sim, temos que trabalhar com esses valores de igualdade, sim, e tem vantagens, sim" ${ }^{\prime 2}$, dizendo que as pessoas com deficiência não seguem o padrão de ser humano imposto pela sociedade. No fundo, o que ocorre aqui é o embate de duas vozes, de dois discursos. A ênfase é uma tentativa de internalizar a inclusão como obrigação. Esses sucessivos "sim” evidenciam uma voz implícita que diz sucessivamente “não".

Claramente, no entanto, não é apontado nenhum ponto positivo, mesmo com a evidência do apelo emotivo ao ser humano. No fundo, o que se vê é somente que o

\footnotetext{
${ }^{11}$ Informação verbal.

${ }^{12}$ Informação verbal.
} 
entrevistado não consegue expressar nenhuma vantagem, uma vez que, na verdade, em sua visão, não há realmente nenhuma.

Sobre as desvantagens, o professor entrevistado diz:

É que nós atendemos um aluno especial, mas nós temos que deixar todos em desvantagens, então nós temos uma sala com quarenta alunos e nós atendemos um e trinta e nove ficam em desvantagem. Prejudica o resto, essa inclusão ${ }^{13}$.

Essa fala, mais uma vez, reflete o preconceito existente na sociedade ao defender a ideia de que o aluno com deficiência, na sala de aula, prejudica o aprendizado de todos os demais. Segundo o professor, esse aluno prejudica e perturba o bom andamento da classe, portanto, ele seria uma ameaça ao sucesso escolar de toda a turma. Essa atitude é mais uma ferramenta utilizada pela ideologia, que Thompson (1995) denomina fragmentação por meio do expurgo do outro, já explicado anteriormente. Para lidar com esse aluno, segundo o professor entrevistado, não basta ser docente, mas deve ser também "psicólogo, psicopedagogo, fisioterapeuta, terapeuta, psiquiatra, neurologista, fazer línguas de sinais" ${ }^{14}$, em suma, deveria ser clínico-geral.

Esse pensamento nos mostra que o professor em questão está bastante afastado da proposta de inclusão, uma vez que ainda vê a deficiência como uma doença que precisa ser tratada, ilustrando, assim, seu pensamento segregador. Ele vê o aluno com deficiência totalmente incapaz. O equívoco que se encontra nas palavras do professor reside no fato de que ele seria o responsável por todas essas tarefas, algo que realmente seria impossível. No entanto, em uma visão não excludente o professor, ao invés de ressaltar a impossibilidade desse aluno com deficiência, indicaria a necessidade de apoio de outros profissionais e contaria com outras práticas, no ambiente escolar, para proporcionar a inclusão desse aluno com deficiência. O docente está afastado, inclusive, do pensamento ultrapassado da integração, que destinava a escola somente para aqueles capazes de se ajustar ao meio escolar. Ele, portanto, pressupõe que o aluno com deficiência não tem capacidade sequer de se integrar, pois é um "problema" que deve ser atendido pela área da saúde e não pela escola.

O professor nominaliza o termo "inclusão", fazendo com que essa perspectiva seja vista como algo externo a qualquer agente. Segundo Thompson (1995), a nominalização ocorre quando sentenças, ou parte delas, descrições da ação e dos participantes nelas

\footnotetext{
${ }^{13}$ Informação verbal.

${ }^{14}$ Informação verbal.
} 
envolvidos, são transformadas em nomes. É como se não houvesse nenhum agente que desenvolvesse esse processo, pois a nominalização apaga os atores sociais e representa processos como coisas, ocorrendo na ausência de um sujeito que produza essas coisas.

Para Fairclough (2001), a nominalização tem o efeito de colocar o processo em segundo plano, já que não especifica os participantes, de forma que agente e paciente são deixados implícitos. Ao falar que a inclusão é uma "coisa", o professor a rejeita e quer estar fora dela e, com isso, pode-se pressupor uma avaliação negativa por parte do docente, uma vez que ele não quer estar dentro desse processo. Isso ilustra que ele o considera algo indesejável.

Mais à frente, na entrevista, o professor constrói um raciocínio para legitimar a ideia de que o aluno com deficiência não deveria estar na escola regular, mas, sim, em outro lugar. Ele coloca empecilhos e se foca nas barreiras arquitetônicas, transparecendo que o melhor para o aluno com deficiência é esse "outro lugar": “Aqui, nós não podemos receber um cadeirante [pessoa que usa cadeiras de rodas]. O banheiro não tem adaptação, temos muitas escadas" "15. Ao evidenciar essas barreiras, ele tenta convencer e justificar que a escola regular não é o lugar ideal para o aluno com deficiência. Mais uma vez, a ideologia dominante pauta-se pela ferramenta de legitimação por meio da racionalização (THOMPSON, 1995), que aqui se expressa pela construção de que o processo de integração é o que deveria prevalecer no meio escolar.

Tal discurso, em nenhuma hipótese, seria o discurso de alguém consciente do processo de inclusão. O docente não chamaria a atenção para as barreiras arquitetônicas, mas, sim, focalizaria a necessidade de mudança, tampouco postularia que o aluno não consegue acompanhar a escola, mas diria que o professor é que deveria prover os meios adequados para que todos aprendam. Por meio da busca de diferentes maneiras de atingir a todos os alunos, o professor respeitaria o ritmo e as necessidades prementes em cada sala de aula.

O corpus aqui analisado revela como a ideologia sutilmente permeia os diferentes discursos, seja mais formal e escrito, seja menos formal e oral. Quando a questão toca em algo tão delicado quanto à educação inclusiva, a ideologia infiltra-se muito mais nos discursos e nas práticas sociais. Isso acontece porque a inclusão das pessoas com deficiência necessita ainda de mudanças sociais relevantes. A começar por meio da tomada de consciência das ideias naturalizadas ou dos preconceitos construídos, para que, consequentemente, as práticas sociais também sejam reformuladas e que todos possam estar realmente inclusos como agentes sociais.

\footnotetext{
${ }^{15}$ Informação verbal.
} 


\section{Considerações finais}

Como vimos, o processo de inclusão é um processo de luta mundial, ainda em processo de efetivação. Suas bases legais em países como o Brasil, por exemplo, ainda são reflexos da ideologia e, por muito tempo, serviram para sustentar a exclusão. Ressalta-se a força social dos textos aqui utilizados, pois se tratam de textos legais. São, portanto, normas para a sociedade. Pensemos, pois: se outros textos podem manipular a prática social, imagine um texto legal que dita regras sociais.

No entanto, é importante que se diga também que, apesar de essa ideologia ser tão forte e estar tão transparente no discurso hegemônico, ela não é um cimento social; houve luta e resistência. A nova política de inclusão é um exemplo cabal dessa tentativa de emancipação, algo que pode ser comprovado nas próprias reinterpretações dos textos, que vem sendo feitas no decorrer da história do país.

Cabe a nós, agora, tomarmos cuidado para que ela não se torne mais uma ideologia, mais uma forma de opressão. Cabe a cada um de nós manter o senso crítico e, assim, resistir a qualquer forma ideológica que possa vir a acontecer ou que já esteja embutida, naturalizada.

\section{Referências}

BRASIL. Constituição da República Federativa do $\quad$ Brasil de 1988 Disponível em http://www.planalto.gov.br/ccivil_03/Constituicao/Constitui\%C3\%A7ao.htm>

ALTHUSSER, L. Aparelhos ideológicos de estado: notas sobre os aparelhos ideológicos de Estado. Rio de Janeiro: Geral, 1985.

BAKHTIN, M. Marxismo e filosofia da linguagem. São Paulo: Hucitec, 1999.

BAUER, M. \& GASKELL, G. Pesquisa qualitativa com texto, imagem e som: um manual prático. Petrópolis: Vozes, 2002.

CHAUI, M. O que é Ideologia. São Paulo: Brasiliense, 2004.

CHOULIARAKI, L. \& FAIRCLOUGH, N. Discourse in late modernity; Rethinking Crítical discourse analysis. Edinbourg: Edinbourg University Press, 1999.

Van DIJK, T. Ideologia: una aproximacion multidisciplinaria. Barcelona: Gedisa, 1999.

EALGLETON, T. Ideologia. São Paulo: Boitempo, 1997.

FAIRCLOUGH, N. Discurso e mudança social. Brasília: Editora Universidade de Brasília, 2001. Language and globalization. New york: Perpetua, 2006.

. Analysing discourse: Textual analisys for social research. Routledge, London, 2003.

FAVERO, E. A. G. Direitos das pessoas com deficiência: garantia de igualdade na diversidade. Rio de Janeiro: WVA, 2004.

FLICK, U. Uma introdução à pesquisa qualitativa. Porto alegre: Bookman, 2004.

FOUCAULT, M. A ordem do discurso. São Paulo: Loyola, 2005.

MINISTERIO DA EDUCAÇÃO. Direito à educação: orientações gerais e marcos legais. Brasília, 2006.

ORLANDI, E. P. O que é lingüística. São Paulo: Braziliense, 2007.

PEDRO, E.R. Análise Crítica do Discurso: uma perspectiva sociopolítica e funcional. Lisboa: Caminho, 1997.

SILVA, M. F. (Orgs.). Educação Inclusiva: uma visão diferente. Editora da UFRN, 2004.

THOMPSON, J. B. Ideologia e cultura moderna: teoria social crítica na era dos meios de comunicação de massa. Petrópolis, Rio de Janeiro: Vozes, 1995.

VIEIRA, J. A. [et al]. Reflexões sobre a língua portuguesa: uma abordagem multimodal. Petrópolis, RJ: Vozes, 2007. As abordagens críticas e não-Críticas em análise do discurso. In: Vieira, Josênia Antunes \& SILVA, Denize Helena Garcia da. (Orgs.). Análise do discurso: percursos teóricos e metodológicos. Brasília: Plano, 2002.

WERNECK, C. Ninguém mais vai ser bonzinho na sociedade inclusiva. Rio de janeiro: WMA, 1997.

WODAK, R \& MEYER, M. Métodos de análisis crítico del discurso. Barcelona: Gedisa, 2001.

WODAK, R. Do que trata a ADC - Um resumo de sua história, conceitos importantes e seus desenvolvimentos. In Revista Linguagem em (Dis)curso. V.4, Santa Catarina: UNISUL, 2004. 